ISSN 1029-8940 (Print)

ISSN 2524-230X (Online)

УДК 54.04:577.113.4

Поступила в редакцию 14.11.2018

https://doi.org/10.29235/1029-8940-2019-64-2-222-228

Received 14.11.2018

\author{
В. М. Королевич ${ }^{1}$ П. Блажинска ${ }^{2}$, А. Сыкула², Е. Лодыга-Хрущинска \\ ${ }^{1}$ Полесский государственный университет, Пинск, Республика Беларусь \\ 2. Лодзинский технический университет, Лодзь, Польша

\section{ДНК-СВЯЗЫВАЮЩИЕ СВОЙСТВА 2'-ГИДРОКСИФЛАВАНОНА И ЕГО ПРОИЗВОДНОГО НА ОСНОВЕ МОДИФИКАЦИИ ШИФФА}

\begin{abstract}
Аннотация. Флаваноиды - крупнейший класс растительных полифенолов. 2'-Гидроксифлаванон относится к производным флавона и первоначально был выделен из растения мимоза пугливая (Mimosa pudica). Данное химическое соединение обладает широким спектром биологической активности, в том числе и способностью к связыванию с ДНК. Нами изучены физико-химические свойства 2'-гидроксифлаванона и его производного на основе модификации Шиффа, а также механизмы их взаимодействия с ДНК. Качественный анализ проведен с помощью ядерного магнитного резонанса. Для анализа стабильности химической структуры производного 2'-гидроксифлаванона на основе модификации Шиффа использовали ультрафиолетовую спектроскопию. 2'-Гидроксифлаванон и его производное фотостабильны в диметилсульфоксиде. Взаимодействие 2'-гидроксифлаванона и его производного происходит по механизму интеркаляции. Изменение структуры молекулы 2'-гидроксифлаванона путем модификации Шиффа приводит к усилению ДНК-связывающих свойств. Высокая аффинность связывания с ДНК 2'-гидроксифлаванона и его производного в форме модификации Шиффа может найти применение при разработке противоопухолевых и антимикробных лекарств.

Ключевые слова: 2'-гидроксифлаванон, модификация Шиффа, ДНК-связывающие свойства, константа связывания с ДНК

Для цитирования: ДНК-связывающие свойства 2'-гидроксифлаванона и его производного на основе модификации Шиффа / В. М. Королевич [и др.] // Вес. Нац. акад. навук Беларусі. Сер. біял. навук. - 2019. - Т. 64, № 2. - С. $222-228$. https://doi.org/10.29235/1029-8940-2019-64-2-222-228
\end{abstract}

\author{
V. M. Korolevich ${ }^{1}$, P. Blazinska ${ }^{2}$, A. Sykula ${ }^{2}$, E. Lodyga-Chruscinska ${ }^{2}$ \\ ${ }^{1}$ Polessky State University, Pinsk, Republic of Belarus \\ ${ }^{2}$ Lodz University of Technology, Lodz, Poland
}

\title{
DNA BINDING PROPERTIES OF 2'-HYDROXYFLAVANON AND SCHIFF BASE DERIVATIVE
}

\begin{abstract}
Flavanoids a class of plant and fungus secondary metabolites. 2'-Hydroxyflavanone was previously isolated from Mimosa pudica (L.) whole plant and was found to exhibit anti-inflammatory effects in vitro and binding with calf timus DNA. There are also reports on anti-inflammatory properties of compounds bearing flavanone/chromone nucleus. The aim of this work was to develop a synthesis of new azomethine compounds derived from flavanones, to examine their spectroscopic properties and interaction with DNA. 2'-Hydroxyflavanone and thiocarbohydrazide were used as substrates in the synthesis. The obtained products were analyzed by $1 \mathrm{H}$ NMR spectroscopy, UVVis. Ultraviolet spectroscopy was used to analyze the chemical-physical properties. Mechanism of interaction of bioactive 2'-hydroxyflavanone with calf thymus deoxyribonucleic acid (DNA) was studied employing UV absorption. 2'-Hydroxyflavanon and 2'HFTCH are photostable in DMSO. The interaction of 2'-hydroxyflavanone and its derivative occurs by the mechanism of intercalation. The change in the structure of the 2'-hydroxyflavanone molecule by Schiff base modification leads to an increase in DNA-binding properties. High binding ability of 2'-hydroxyflavanone with DNA may be useful for development of new anti-inflammatory and antimicrobial remedies.

Keywords: 2'-hydroxyflavanone, calf timus DNA, nuclear magnetic resonance

For citation: Korolevich V. M., Blazinska P., Sykula A., Lodyga-Chruscinska E. DNA binding properties of 2'-hydroxyflavanon and Schiff base derivative. Vestsi Natsyyanal'nai akademii navuk Belarusi. Seryya biyalagichnych navuk $=$ Proceedings of the National Academy of Sciences of Belarus. Biological series, 2019, vol. 64, no. 2, pp. $222-228$ (in Russian). https://doi.org/10.29235/1029-8940-2019-64-2-222-228
\end{abstract}

Введение. Флаваноиды представляют собой биологически активные соединения, относящиеся к классу полифенольных соединений. Структурную основу флавоноидов составляют два бензольных ядра, соединенных друг с другом трехуглеродным фрагментом согласно формуле $\mathrm{C}_{6}-\mathrm{C}_{3}-\mathrm{C}_{6}$. Флаваноиды обладают широким спектром биологической активности, включая противораковые, противомалярийные, антиоксидантные, противоинфекционные свойства и др. [1]. Эффективность биологического действия определяется структурными особенностями их 
молекулы. В частности, методом анализа соотношения структура - функция (QSAR, quantitative structure - activity relationships) молекул флавоноидов установлено, что антиоксидантная активность последних зависит от положения ОН-групп в молекуле, наличия или отсутствия двойной связи в кольце С, а также от формы молекулы [2].

Среди флавоноидов наибольшим антибактериальным и противоопухолевым эффектом обладают флаваноны. В частности, 2'-гидроксифлаванон подавляет развитие рака молочной железы в результате ингибирования пролиферации и васкуляризации опухоли [3], индуцирует апоптоз клеток рака толстой кишки [4], способствует нормальной дифференцировке клеток в карциноме почек [5]. Антибактериальные свойства 2'-гидроксифлаванона показаны для бактерий E. coli, B. subtilis, S. aureus и связаны с подавлением роста культуры [6]. Помимо антиоксидантной активности одним из возможных механизмов, объясняющих противоопухолевые и антибактериальные свойства 2'-гидроксифлаванона, является ранее продемонстрированная способность данного соединения к взаимодействию с ДНК, посредством чего может осуществляться регуляция экспрессии генов опухолевых и бактериальных клеток [7].

В то же время структурные изменения флавоноидов и других молекул, связанные с модификацией Шиффа, приводят к значительному усилению противомикробной и противоопухолевой активности. Основания Шиффа проявляют активность против грамположительных бактерий, таких как $S$. aureus, и грамотрицательных бактерий - E. coli, P. aeruginosa. Среди флаваноидов с модификацией Шиффа $\mathrm{N}$-(салицилиден)-2-гидроксианилин показал эффективность против M. tuberculosis [8]. Основания Шиффа с 2,4-дихлор-5-фторфенильным фрагментом эффективны также при ингибировании роста бактерий S. aureus, E. coli, P. aeruginosa и K. pneumoniae [9]. Гесперетин с модификацией Шиффа полностью подавлял рост культуры $S$. aureus [10]. В то же время механизмы, приводящие к усилению биологической активности флавоноидов в случае модификации Шиффа, практически не изучены.

Исследование взаимодействий флаваноидов с ДНК может помочь в разработке терапевтических агентов с целью регуляции экспрессии генов. Малые молекулы способны связываться с ДНК с помощью следующих механизмов [11]:

интеркалирующего связывания, когда молекула включается в пары оснований нуклеиновых кислот;

связывания в малой или большой бороздках двойной спирали ДНК путем ван-дер-ваальсовых взаимодействий;

электростатического взаимодействия между отрицательно заряженной фосфатной группой ДНК и катионным концом молекулы.

Среди перечисленных выше механизмов малые молекулы, интеркалированные в ДНК, более устойчивы к воздействию внешних агентов. Данный механизм связывания с ДНК наблюдается также у флаваноидов [12].

Цель настоящей работы - исследование физико-химических свойств 2'-гидроксифлаванона и его производного на основе модификации Шиффа, а также механизмов их взаимодействия с ДНК.

Для достижения цели нашего исследования были поставлены следующие задачи:

проанализировать физико-химические свойства 2'-гидроксифлаванона и его производного;

изучить особенности взаимодействия 2'-гидроксифлаванона и его производного с ДНК;

определить константу связывания 2'-гидроксифлаванона и его производного с ДНК.

Материалы и методы исследования. Производное 2'-гидроксифлаванона на основе модификации Шиффа с использованием тиокарбогидразида обозначено нами как 2'HFTCH. Для синтеза 2'HFTCH использовали тиокарбогидразид и 2'-гидроксифлаванон (Sigma Aldrich, CША) coгласно методу, приведенному в работе [13]. После полного растворения тиокарбогидразида в колбу с $\mathrm{C}_{2} \mathrm{H}_{5} \mathrm{OH}$ добавляли 2'-гидроксифлаванон и полученный раствор, постоянно помешивая, в течение 25 ч нагревали до $89{ }^{\circ} \mathrm{C}$ в присутствии $99 \%$ концентрированной серной кислоты. Полученный желтый осадок фильтровали, промывали холодной водой и высушивали.

Качественный анализ синтезированного соединения - производного 2'-гидроксифлаванона на основе модификации Шиффа - был проведен с помощью ядерного магнитного резонанса (ЯМР) 
и ультрафиолетовой спектроскопии. Спектр ЯМР был записан на спектрометре Bruker AV200 $200 \mathrm{MH} \mathrm{в} \mathrm{ДМСО} \mathrm{с} \mathrm{тетраметилсиланом} \mathrm{в} \mathrm{качестве} \mathrm{внутреннего} \mathrm{стандарта.} \mathrm{Для} \mathrm{изучения} \mathrm{фотоста-}$ бильности использовали растворы 2'-гидроксифлаванона и производного 2'-гидроксифлаванона на основе модификации Шиффа в концентрации 0,01 М (ДМСО). Фотостабильность 2'-гидроксифлаванона и его производного исследовали с помощью ультрафиолетовой спектроскопии при длине волны 323 нм.

Для определения констант связывания с ДНК 2'-гидроксифлаванона и 2'HFTCH с ДНК осуществляли путем смешивания раствора исследуемого флавоноида (25 мкМ) с растворами ДНК (CT-DNA, Sigma, Германия) в концентрации от 0 до 25 мкМ и затем рассчитывали спектры поглощения полученных растворов. Растворы CT-DNA и флавоноидов готовили на фосфатном буфере (50 мМ калий-фосфатный буфер, pH 7,4). Для последующих расчетов использовали $\varepsilon_{260}=6600$ $\mathrm{M}^{-1} \cdot \mathrm{cm}^{-1}$. Все измерения проводили после инкубации в течение 10 мин при комнатной температуpe. Анализ спектров поглощения осуществляли с помощью программы OriginPro8 (OriginLab, США). Константу связывания рассчитывали по уравнению

$$
[\mathrm{DNA}] /\left(\varepsilon_{a}-\varepsilon_{f}\right)=[\mathrm{DNA}] /\left(\varepsilon_{a}-\varepsilon_{b}\right)+1 / \mathrm{Kb}\left(\varepsilon_{a}-\varepsilon_{f}\right),
$$

где [DNA] - концентрация ДНК, $\varepsilon_{a}-$ коэффициент молярного поглощения комплекса исследуемого флавоноида с ДНК, $\varepsilon_{f}-$ коэффициент молярного поглощения исследуемого флавоноида в отсутствие ДНК, $\varepsilon_{b}-$ коэффициент молярного поглощения полностью связанного соединения и его производного с ДНК. Формула $[\mathrm{DNA}] /\left(\varepsilon_{a}-\varepsilon_{f}\right)$ в соотношении с [DNA] дает угловой коэффициент $-1 /\left[\varepsilon_{a}-\varepsilon_{f}\right]$, а линейный коэффициент равен $1 / \mathrm{Kb}\left(\varepsilon_{b}-\varepsilon_{f}\right)$. Константа связывания $(\mathrm{Kb})$ определяется через отношение углового коэффициента к линейному [14].

Результаты и их обсуждение. Химическое уравнение реакции синтеза производного на основе модификации Шиффа представлено на рис. 1. В состав молекулы вновь синтезированного соединения входят две молекулы 2'-гидроксифлаванона, соединенные между собой тиокарбогидразильной группой.

С целью исключения изменения химической структуры 2'-гидроксифлаванона и 2'HFTCH нами была проверена фотостабильность соединений в ДМСО в течение 4 ч (рис. 2).

Наблюдаемые на рис. 2 незначительные изменения оптической плотности 2 '-гидроксифлаванона (от 0,2566 до 0,27096 (рис. 2, a) и его производного (от 0,50828 до 0,49608 (рис. $2, b$ ) свидетельствуют о стабильности данных химический соединений в ДМСО.

Чистоту производного на основе модификации Шиффа 2'HFTCH проверяли с помощью метода ЯМР (рис. 3). Характерные области химических сдвигов протонов различных фрагментов (NH, OH, H, $\mathrm{H}_{2} \mathrm{O}, \mathrm{DMSO}$ ) в спектре ЯMР указывали на наличие определенных атомных групп в молекуле 2'HFTCH.

На рис. 4 представлены спектры поглощения 2'-гидроксифлаванона и его производного на основе модификации Шиффа 2'HFTCH при наличии и отсутствии ДНК, характеризующие ДНК-связывающие свойства исследуемых соединений.

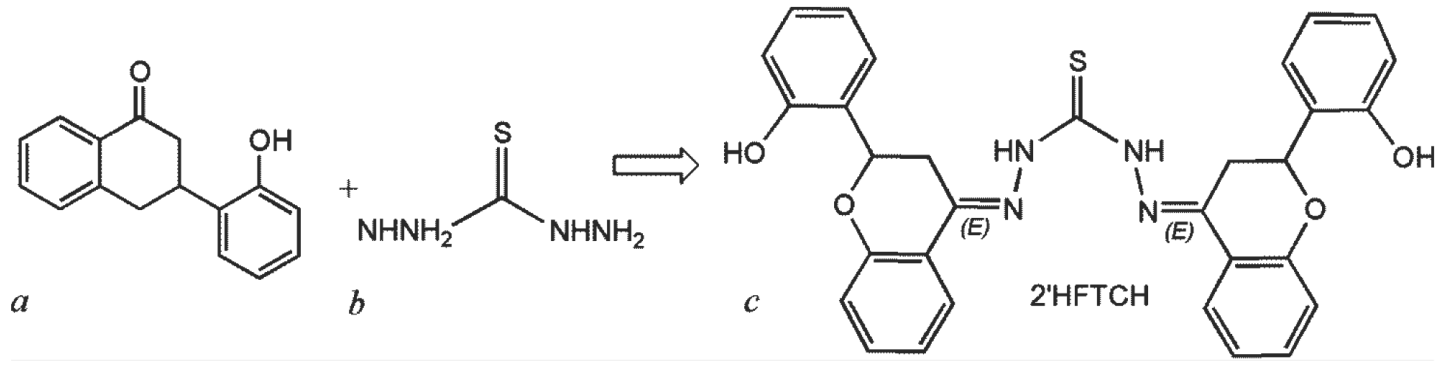

Рис. 1. Реакция синтеза производного 2'-гидроксифлаванона на основе модификации Шиффа: $a-2^{\prime}$-гидроксифлаванон; $b$ - тиокарбогидразид; $c-2^{\prime} \mathrm{HFTCH}$

Fig. 1. Synthesis of Shiff base derivative of the 2'-hydroxyflavanone: $a-2$ '-hydroxyflavanone; $b$ - tiocarbohydrazide; $c-2^{\prime} \mathrm{HFTCH}$ 

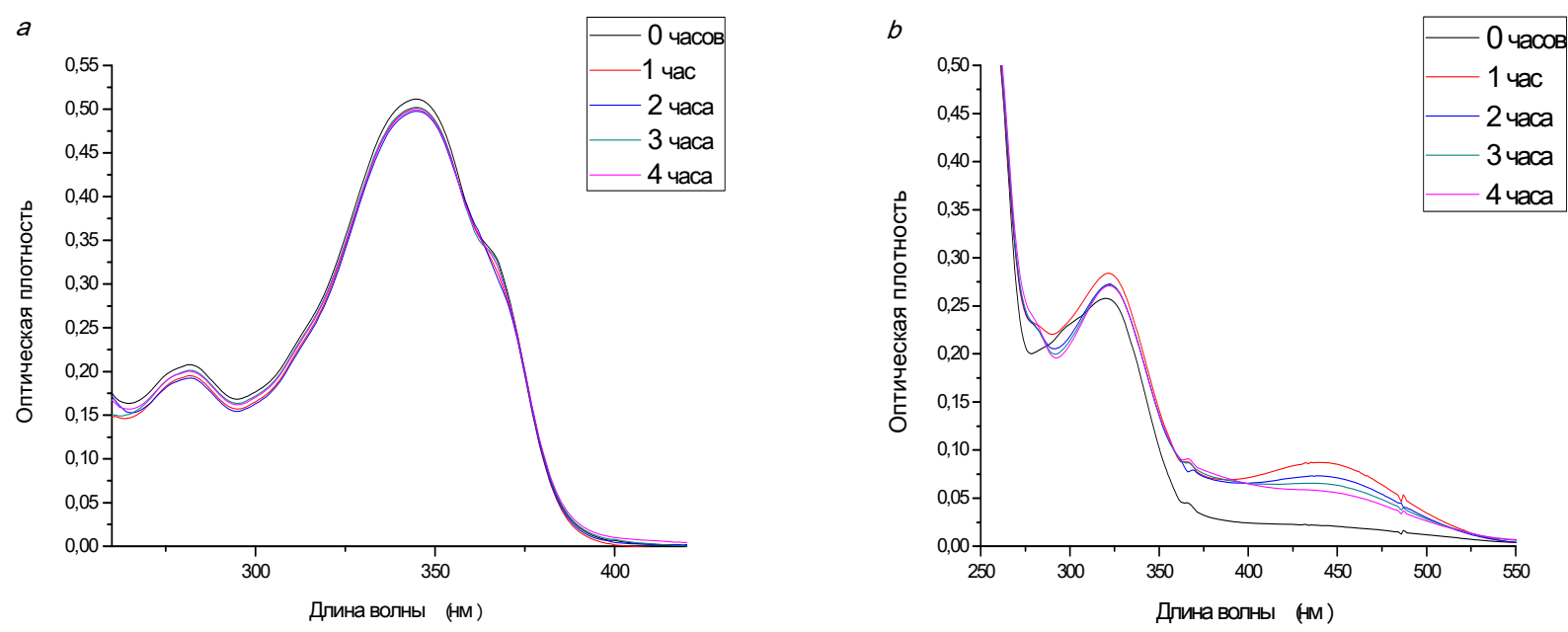

Рис. 2. Фотостабильность 2'-гидроксифлаванона (a) и $2^{\prime} \mathrm{HFTCH} \mathrm{(b)}$

Fig. 2. Fotostability of $2^{\prime}$-hydroxyflavanone $(a)$ and $2^{\prime} \mathrm{HFTCH}(b)$

A.

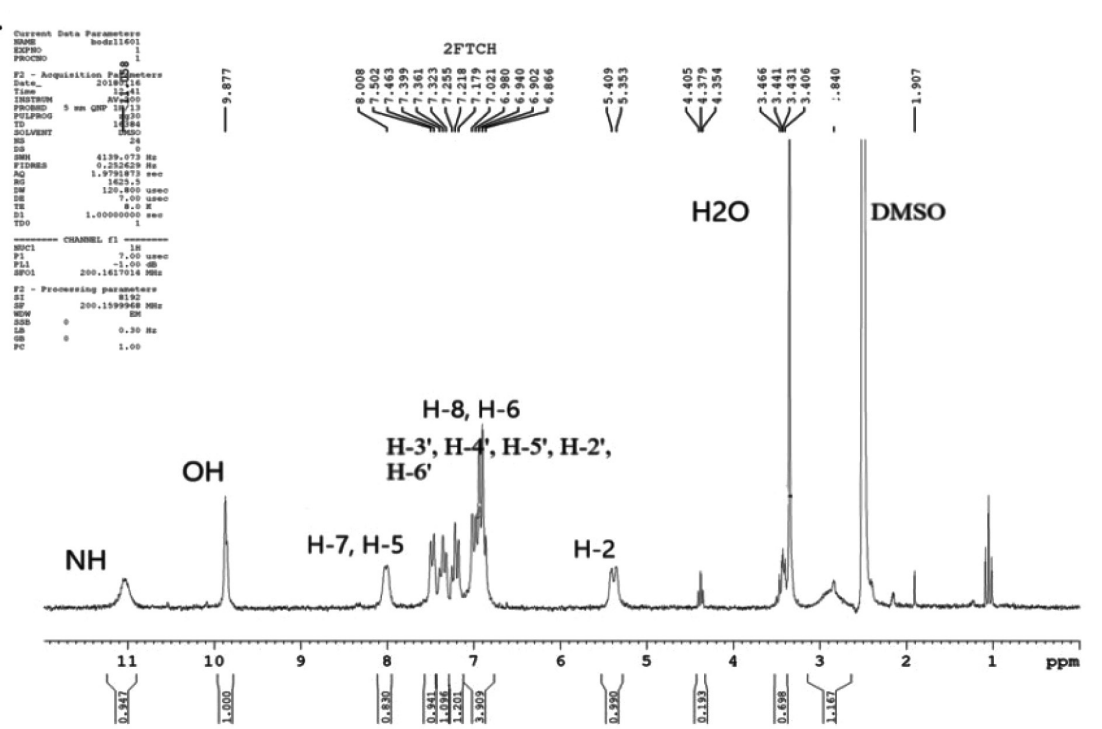

Рис. 3. Спектр ядерного магнитного резонанса 2'HFTCH

Fig. 3. Nuclear magnetic resonance spectra $2^{\prime} \mathrm{HFTCH}$

Основываясь на том, что фенольный каркас молекул флавоноидов содержит 15 атомов углерода, образующих два ароматических кольца (рис. $4, a, b$ ), которые соединены тремя углеродными атомами, исследуемый $2^{\prime} \mathrm{HFTCH}$ находится в системе В (второй пик на рис. 4). Исходя из этого, в спектре 2'-гидроксифлаванона максимальный пик приходится на длину волны 323 нм. В случае с производным на основе модификации Шиффа 2'HFTCH максимальный пик приходится на длину волны 357 нм. При добавлении ДНК к раствору 2'-гидроксифлавана с фосфатным буфером происходит незначительный сдвиг (на 1 нм) максимума поглощения при $\lambda_{\max }=323$ нм, в то время как при добавлении ДНК к 2'HFTCH в фосфатном буфере наблюдается значительный сдвиг (на 10 нм) максимума поглощения в фиолетовую (коротковолновую) сторону (синее смещение) при $\lambda_{\max }=357$ нм. Это обусловлено тем, что взаимодействие между ДНК и исследуемыми соединениями происходит путем интеркаляции. Синий сдвиг может быть обусловлен Н-связыванием между интеркалирующим соединением и ДНК [15].

Значительное изменение интенсивности поглощения наблюдалось в двух случаях: на спектре с 2'-гидроксифлаванона экстинкция увеличилась от 0,08301 (оптическая плотность несвязанной 

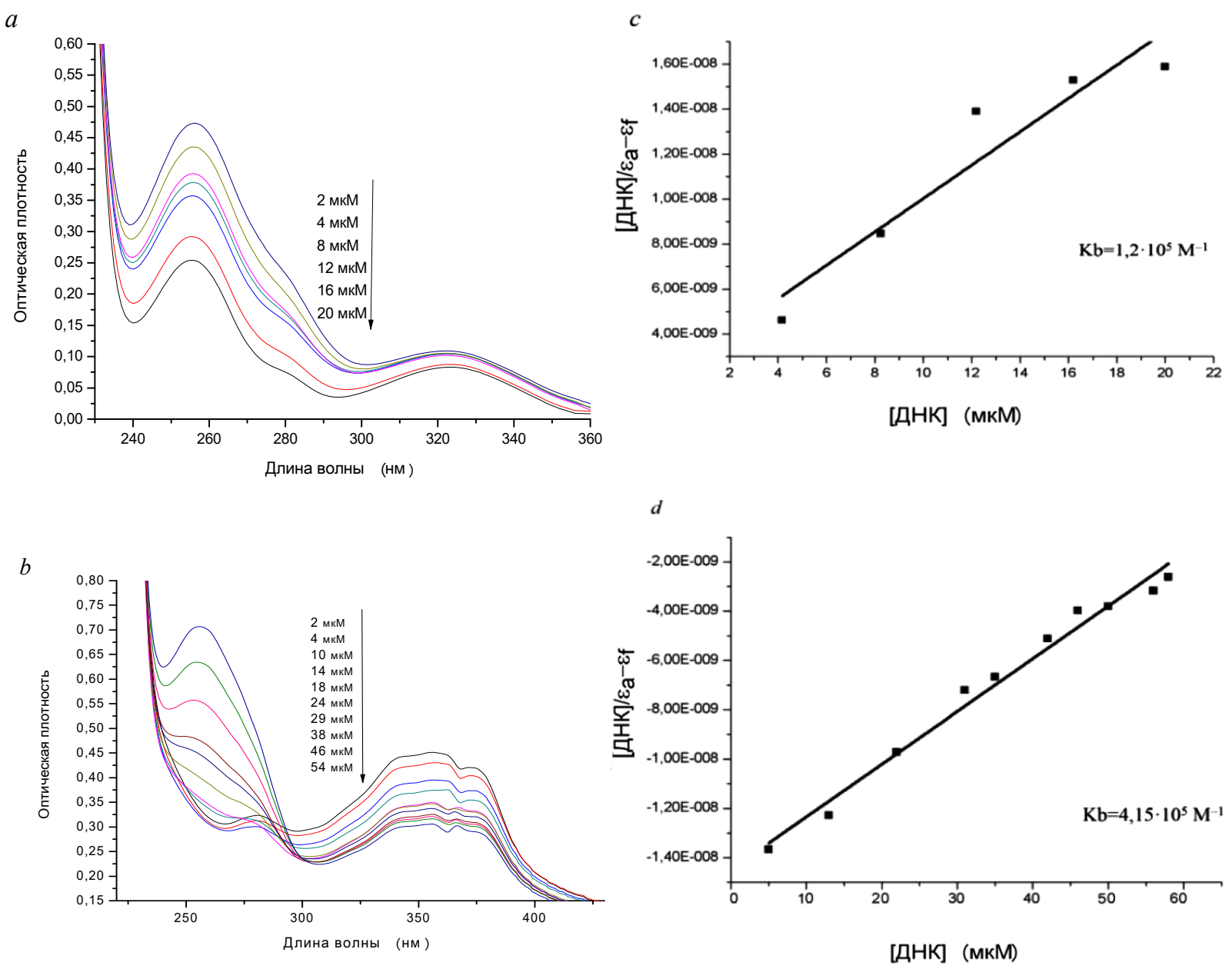

Рис. 4. Спектры поглощения и константы связывания с ДНК 2'-гидроксифлаванона и 2'НFТСН при различных концентрациях ДНК тимуса теленка: $a, b$ - спектры поглощения 2'-гидроксифлаванона и 2'HFTCH соответственно; $c, d$ - графики определения константы связывания с ДНК для 2'-гидроксифлаванона и 2'НFТСН соответственно. Время инкубации 10 мин. Стрелка показывает направление изменения оптической плотности при добавлении различных концентраций ДНК. Концентрация исследуемого флавоноида во всех пробах $2,5 \cdot 10^{-5} \mathrm{M}$. Kb - константа связывания с ДНК

Fig. 4. Absorption spectra and binding constant with CT-DNA of 2'-hydroxyflavanone and 2'HFTCH at varicose concentration of CT-DNA: $a, b$-absorption spectra of 2 'hedroxyflavanone and $2^{\prime} \mathrm{HFTCH}$, respectively; $c, d$ - plots of determination binding constant of CT-DNA for 2'hydroxyflavanone and $2^{\prime} \mathrm{HFTCH}$, respectively. Incubation time 10 minutes. The arrow shows the direction of the change wavelength when adding different concentration of CT-DNA. The concentration of the flavanoids in all of samples are $2.5 \cdot 10^{-5} \mathrm{M}$. $\mathrm{Kb}$ - binding constant with DNA

формы флаваноида) до 0,10905 (при максимальной концентрации ДНК 20 мкМ), а на спектре с 2'HFTCH оптическая плотность снизилась с 0,45087 (оптическая плотность несвязанной формы флаваноида) до 0,34686 (при максимальной концентрации ДНК 54 мкМ). Наблюдаемое изменение оптической плотности доказывает взаимодействие исследуемых флавоноидов с ДНК.

Константны связывания $(\mathrm{Kb})$ 2'-гидроксифлаванона и его производного на основе модификации Шиффа 2'HFTCH с ДНК определяли с помощью графиков, отражающих отношение [DNA]/ $\left(\varepsilon_{a}-\varepsilon_{f}\right)$ к [DNA] (рис. $\left.4, c, d\right)$. Константа связывания с ДНК для 2'-гидроксифлаванона составила $1,2 \cdot 10^{5} \mathrm{M}^{-1}$, а для производного на основе модификации Шиффа $2^{\prime} \mathrm{HFTCH}-4,15 \cdot 10^{5} \mathrm{M}^{-1}$. Более высокое значение $\mathrm{Kb}$ для $2^{\prime} \mathrm{HFTCH}$ свидетельствует о его более высоких ДНК-связывающих свойствах.

Заключение. Согласно полученным данным, 2'-гидроксифлаванон и его производное 2'HFTCH фотостабильны в ДМСО. Это является хорошим результатом, так как их химическая структура остается постоянной на протяжении всего эксперимента. Взаимодействие 2 '-гидроксифлаванона 
и его производного на основе модификации Шиффа $2^{\prime} \mathrm{HFTCH} \mathrm{происходит} \mathrm{по} \mathrm{механизму} \mathrm{ин-}$ теркаляции. Изменение структуры молекулы 2'-гидроксифлаванона путем модификации Шиффа приводит к усилению ДНК-связывающих свойств. Таким образом, ДНК является мишенью в клетке для 2'-гидроксифлаванона и его производного на основе модификации Шиффа. Высокая аффинность связывания с ДНК 2'-гидроксифлаванона и его производных в форме модификации Шиффа может найти применение при разработке противоопухолевых и антимикробных лекарств.

\section{Список использованных источников}

1. Flavonoid glucosides are hydrolyzed and thus activated in the oral cavity in humans / T. Walle [et al.] // J. Nutr. - 2005. Vol. 135, N 1. - P. 48-52. https://doi.org/10.1093/jn/135.1.48

2. The interaction of flavonoids with mitochondria: effects on energetic processes / D. J. Dorta [et al.] // Chem. Biol. Interact. - 2005. - Vol. 152, N 2-3. - P. 67-78. https://doi.org/10.1016/j.cbi.2005.02.004

3. Denny, B. J. Antagonistic interactions between the flavonoids hesperetin and naringenin and beta-lactam antibiotics against Staphylococcus aureus / B. J. Denny, P. W. West, T. C. Mathew // Br. J. Biomed. Sci. - 2008. - Vol. 65, N 3. - P. 145147. https://doi.org/10.1080/09674845.2008.11732819

4. A Quantitative Structure-Activity Relationship (QSAR) study of the antioxidant activity of flavonoids / B. F. Rasulev [et al.] // QSAR Combinatorial Sci. - 2005. - Vol. 24, N 9. - P. 1056-1065. https://doi.org/10.1002/qsar.200430013

5. Anti-inflammatory activity of quercetin and isoquercitrin in experimental murine allergic asthma / A. P. Rogerio [et al.] // Inflamm. Res. - 2007. - Vol. 56, N 10. - P. 402-408. https://doi.org/10.1007/s00011-007-7005-6

6. 2'-Hydroxyflavanone effectively targets RLIP76-mediated drug transport and regulates critical signaling networks in breast cancer / L. D. Nagaprashantha [et al.] // Oncotarget. - 2018. - Vol. 9, N 26. - P. 18053-18068. https://doi.org/10.18632/ oncotarget. 24720

7. Hegde, A. H. Interaction of antioxidant flavonoids with calf thymus DNA analyzed by spectroscopic and electrochemical methods / A. H. Hegde, S. N. Prashanth, J. Seetharamappa // J. Pharmaceut. Biomed. Analysis. - 2012. - Vol. 63. - P. 40-46. https://doi.org/10.1016/j.jpba.2012.01.034

8. Schiff bases: a short review of their antimicrobial activities / C. M. da Silva [et al.] // J. Adv. Res. - 2011. - Vol. 2, N 1. P. 1-8. https://doi.org/10.1016/j.jare.2010.05.004

9. Schiff bases as an antimicrobial agent / A. Rani [et al.] // JBCS. - 2015. - Vol. 2, N 1. - P. 62-91.

10. Chelating ability and biological activity of hesperetin Schiff base / E. Lodyga-Chruscinska [et al.] // J. Inorg. Biochem. 2018. - Vol. 143. - P. 34-47. https://doi.org/10.1016/j.jinorgbio.2014.11.005

11. Exploration of mode of binding of ctDNA with 3-hydroxyflavone: a contrast to the mode of binding with flavonoids having additional hydroxyl groups / J. Barnali [et al.] // J. Phys. Chem. - 2011. - Vol. 116, N 1. - P. 639-645. https://doi.org/ $10.1021 / \mathrm{jp} 2094824$

12. Physicochemical, antioxidant, DNA cleaving properties and antimicrobial activity of fisetin-copper chelates / E. Łodyga-Chruscińska [et al.] // J. Inorg. Biochem. - 2018. - Vol. 180. - P. 101-118. https://doi.org/10.1016/j.jinorgbio.2017.12.006

13. Mixed-ligand complexes of ruthenium (II): factors governing binding to DNA / A. M. Pyle [et al.] // J. Am. Chem. Soc. - 1989. - Vol. 111, N 8. - P. 3051-3058. https://doi.org/10.1021/ja00190a046

14. Interaction of chalcones with ct-dna by spectrophotometric analysis and theoreticalsimulations / X. Zarate [et al.] // Química Nova. - 2016. - Vol. 39, N 8. - P. 914-918. https://doi.org/10.5935/0100-4042.20160114

15. Kumaramangalam, J. DNA/protein binding and cytotoxicity studies of copper(II) complexes containing N,N0,N00trisubstituted guanidine ligands / J. Kumaramangalam, S. Nagamani, S. P. Nattamai // RSC Advances. - 2014. - Vol. 4, N 33. P. 17179-17195. https://doi.org/10.1039/c4ra01459f

\section{References}

1. Walle T., Browning A. M., Steed L. L., Reed S. G., Walle U. K. Flavonoid glucosides are hydrolyzed and thus activated in the oral cavity in humans. Journal of Nutrition, 2005, vol. 135, no. 1, pp. 48-52. https://doi.org/10.1093/jn/135.1.48

2. Dorta D. J., Pigoso A. A., Mingatto F. E., Rodrigues T., Prado I. M. R., Helena A. F. C., Uyemura S. A., Santos A. C., Curti C. The interaction of flavonoids with mitochondria: effects on energetic processes. Chemico-Biological Interactions, 2005, vol. 152, no. 2-3, pp. 67-78. https://doi.org/10.1016/j.cbi.2005.02.004

3. Denny B. J., West P. W., Mathew T. C. Antagonistic interactions between the flavonoids hesperetin and naringenin and beta-lactam antibiotics against Staphylococcus aureus. British Journal of Biomedical Science, 2008, vol. 65, no. 3, pp. $145-147$. https://doi.org/10.1080/09674845.2008.11732819

4. Rasulev B. F., Abdullaev N. D., Syrov V. N., Leszczynski J. A Quantitative Structure-Activity Relationship (QSAR) study of the antioxidant activity of flavonoids. QSAR \& Combinatorial Science, 2005, vol. 24, no. 9, pp. 1056-1065. https:// doi.org/10.1002/qsar.200430013

5. Rogerio A. P., Kanashiro A., Fontanari C., da Silva E. V. G., Lucisano-Valim Y. M., Soares E. G., Faccioli L. H. Antiinflammatory activity of quercetin and isoquercitrin in experimental murine allergic asthma. Inflammation Research, 2007, vol. 56, no. 10, pp. 402-408. https://doi.org/10.1007/s00011-007-7005-6 
6. Nagaprashantha L. D., Singhal J., Li H., Warden Ch., Liu X., Horne D., Awasthi S., Salgia R., Singhal S. S. 2'-Hydroxyflavanone effectively targets RLIP76-mediated drug transport and regulates critical signaling networks in breast cancer. Oncotarget, 2018, vol. 9, no. 26, pp. 18053-18068. https://doi.org/10.18632/oncotarget.24720

7. Hegde A. H., Prashanth S. N., Seetharamappa J. Interaction of antioxidant flavonoids with calf thymus DNA analyzed by spectroscopic and electrochemical methods. Journal of Pharmaceutical and Biomedical Analysis, 2012, vol. 63, pp. 40-46. https://doi.org/10.1016/j.jpba.2012.01.034

8. Da Silva C. M., da Silva D. L., Modolo L. V., Alves R. B., de Resende M. A., Martins C. V. B., de Fátima Â. Schiff bases: a short review of their antimicrobial activities. Journal of Advanced Research, 2011, vol. 2, no. 1, pp. 1-8. https://doi. org/10.1016/j.jare.2010.05.004

9. Rani A., Kumar M., Khare R., Tuli H. S. Schiff bases as an antimicrobial agent. JBCS, 2015, vol. 2, no. 1, pp. 62-91.

10. Lodyga-Chruscinska E., Symonowicz M., Sykula A., Bujacz A., Garribba E., Rowinska-Zyrek M. [et al.]. Chelating ability and biological activity of hesperetin Schiff base. Journal of Inorganic Biochemistry, 2018, vol. 143, pp. 34-47. https:// doi.org/10.1016/j.jinorgbio.2014.11.005

11. Barnali J., Sudipta S., Debanjana G., Debosreeta B., Nitin C. Exploration of mode of binding of ctDNA with 3-hydroxyflavone: a contrast to the mode of binding with flavonoids having additional hydroxyl groups. Journal of Physical Chemistry, 2011, vol. 116, no. 1, pp. 639-645. https://doi.org/10.1021/jp2094824

12. Łodyga-Chruscińska E., Pilo M., Zucca A., Garribba E., Klewicka E., Symonowicza M., Chruscinki L., Cheshevik V. Physicochemical, antioxidant, DNA cleaving properties and antimicrobial activity of fisetin-copper chelates. Journal of Inorganic Biochemistry, 2018, vol. 180, pp. 101-118. https://doi.org/10.1016/j.jinorgbio.2017.12.006

13. Pyle A. M., Rehmann J. P., Meshoyrer R., Kumar C. V., Turro N. J., Barton J. K. Mixed-ligand complexes of ruthenium (II): factors governing binding to DNA. Journal of the American Chemical Society, 1989, vol. 111, no. 8, pp. 3051-3058. https://doi.org/10.1021/ja00190a046

14. Zarate X., Schott E., Escobar C. A., Lopez-Castro R., Echeverria C., Alvarado-Soto L., Ramirez-Tagle R. Interaction of chalcones with ct-dna by spectrophotometric analysis and theoreticalsimulations. Química Nova, 2016, vol. 39, no. 8, pp. $914-918$. https://doi.org/10.5935/0100-4042.20160114

15. Jeyalakshmi K., Selvakumaran N., Bhuvanesh N. S. P., Sreekanth A., Karvembu R. DNA/protein binding and cytotoxicity studies of copper(II) complexes containing N,N0,N00-trisubstituted guanidine ligands. RSC Advances, 2014, vol. 4, no. 33, pp. 17179-17195. https://doi.org/10.1039/c4ra01459f

\section{Информация об авторах}

Королевич Виолетта Михайловна - магистр биол. наук. Полесский государственный университет (ул. Днепровской флотилии, 23, 225710, г. Пинск, Брестская область, Республика Беларусь). E-mail: Violetta.Korolevich@mail.ru

Паулина Блажинска - магистр хим. наук, аспирант. Лодзинский технический университет (ул. Стефановски, 4/10, 90-924, Лодзь, Польша). E-mail: Paulina.blazinska@, edu.p.lodz.pl

Анна Сыкула - канд. хим. наук, доцент. Лодзинский технический университет (ул. Стефановски, 4/10, 90-924, Лодзь, Польша). E-mail: Anna.sykula@p.lodz.pl

Елизавета Лодыга-Хрущинска - д-р хим. наук, профессор. Лодзинский технический университет (ул. Стефановски, 4/10, 90-924, г. Лодзь, Польша). E-mail: Elalodyg@, p.lodz.pl

\section{Information about the authors}

Violetta M. Korolevich - Master of Biology. Polessky State University (23, Dneprovskaya Flotiliya Str., 225710, Pinsk, Republic of Belarus). E-mail: Violetta.Korolevich@mail.ru

Paulina Błazińska - Master of Chemistry, Postgraduate student. Lodz University of Technology (4/10, Stefanowskii Str., 90-924, Lodz, Poland). E-mail: paulina.blazinska@edu.p.lodz.pl Anna Sykuła - Ph. D. (Chem.), Assistant Professor. Lodz University of Technology (4/10, Stefanowskii Str., 90-924, Lodz, Poland). E-mail: anna.sykula@p.lodz.pl

Elżbieta Lodyga-Chruścińska - D. Sc. (Chem.), Professor. Lodz University of Technology (4/10, Stefanowskii Str., 90-924, Lodz, Poland). E-mail: elalodyg@p.lodz.pl 